Thélème. Revista Complutense de Estudios Franceses

ISSN-e 1989-8193

\title{
Bandole versus Justine: el sistema del alma del mundo en La Nouvelle Justine de Sade
}

\author{
Natalia Zorrilla ${ }^{1}$
}

Recibido: 18/01/2020 / Aceptado: 05/05/2020

Resumen: Este artículo se propone examinar la apropiación irónica que realiza Donatien Alphonse François de Sade del llamado "sistema del alma del mundo" en La Nouvelle Justine. Nuestro objetivo es mostrar cómo Sade subvierte tal sistema filosófico, originalmente asociado a posiciones inmaterialistas pitagórico-platónicas, para así transformarlo en una cosmovisión inmanentista-materialista. A fin de lograrlo, nos concentraremos en la composición del personaje libertino Bandole y su diálogo con la protagonista de la novela. Estudiaremos la reconstrucción de estas ideas acerca del alma del mundo que realizan autores frecuentemente leídos por Sade como Pierre Bayle y Nicolas Fréret, atendiendo asimismo a su vinculación con el pensamiento de Baruch Spinoza. A través de este artículo, nos proponemos ofrecer nuevas perspectivas desde donde revisar y evaluar el polémico compromiso (o ausencia de él) que exhibiría la obra libertina de Sade con la difusión de las ideas y proclamas del movimiento ilustrado.

Palabras clave: Sade; sistema del alma del mundo; materialismo; Ilustración.

\section{[fr] Bandole versus Justine : le système de l'âme du monde dans La Nouvelle Justine de Sade}

Résumé : Cet article a pour but d'examiner l'appropriation ironique faite par Donatien Alphonse François de Sade du « système de l'âme du monde » dans La Nouvelle Justine. Nous visons à montrer comment Sade subvertit ce système philosophique, originellement associé à la pensée immatérialiste pythagorico-platonicienne, pour le transformer en une vision du monde immanentiste-matérialiste. Pour atteindre notre objectif, nous nous concentrons sur la caractérisation que Sade offre du libertin Bandole et sur son dialogue avec Justine. Nous étudions la reconstruction historico-conceptuelle des expressions philosophiques et théologiques du système de l'âme du monde produite par certains auteurs que Sade lisait fréquemment, comme Pierre Bayle et Nicolas Fréret, en faisant attention à leur liaison avec la pensée de Baruch Spinoza. Nous nous proposons d'évaluer et de réfléchir sur le polémique engagement (ou sur l'absence de celui-ci) des romans libertins de Sade avec la diffusion des principales proclamations et idées des Lumières.

Mots clés : Sade ; système de l'âme du monde ; matérialisme ; les Lumières.

\section{[en] Bandole versus Justine: The World's Soul System in Sade's La Nouvelle Justine}

\begin{abstract}
This article seeks to examine Donatien Alphonse François de Sade's ironic appropriation of the "world's soul system" in La Nouvelle Justine. Our objective is to show how Sade subverts said philosophical system, originally associated with immaterialist Pythagorean-Platonic thought, in order to transform it into an immanentist-materialist worldview. In order to accomplish this task, we concentrate on Sade's characterization of the libertine Bandole and his dialogue with Justine. We also study the historical-conceptual reconstruction of philosophical and theological expressions of the world's soul system produced by authors that Sade frequently read, such as Pierre Bayle and Nicolas Fréret. Of special relevance will be the link between those expressions and Baruch Spinoza's thought. This articles evaluates the controversial engagement (or lack thereof) that Sade's libertine novels exhibit with respect to the diffusion of the Enlightenment's key proclamations and ideas. Keywords: Sade; world's soul system; materialism; Enlightenment.
\end{abstract}

Sumario : 1. Introducción. 2. Bayle, Fréret: un spinozismo "figurado". 3. Bandole. 4. Conclusión. 5. Referencias bibliográficas. 
Cómo citar: Zorrilla, N. (2020). "Bandole versus Justine: el sistema del alma del mundo en La Nouvelle Justine de Sade". Thélème. Revista Complutense de Estudios Franceses. Vol. 35, Núm. 2: 291-299.

\section{Introducción}

Durante buena parte del siglo XX, intelectuales como Adorno y Horkheimer (1998), Guillaume Apollinaire (1909), Georges Bataille (1990, 2011), Roland Barthes (1971), Maurice Blanchot (1949), Albert Camus (1957), Simone de Beauvoir (1972), Gilles Deleuze (1967), Michel Foucault (1990, 1994, 1999, 2013), y Pierre Klossowski (1967) se dedicaron a interpretar la obra de Sade. Reaccionando en parte contra la "psiquiatrización" de Sade y contra las grandes dificultades que impedían el acceso a sus escritos, vieron en él un autor clandestino, pornógrafo sulfuroso, pero también un intelectual del horror, que visibilizaba a través de su prosa filosófica distintas problemáticas concernientes a la condición humana, al sentido de la existencia y a la escritura. Cuando a fines de ese siglo la obra sadeana comienza a ser considerada un objeto de estudio posible en el campo de la investigación académica, debido a las contribuciones de Philippe Roger (1976), Annie Le Brun (1993), Alice Laborde (1974), Jean Deprun (1970, 1976, 1980) y Michel Delon (Sade, 1990-1998), el interés por devolver a Sade a su contexto histórico permea tales aproximaciones al pensamiento del furtivo autor. En el mundo hispanoparlante, los textos de Sade también han sido traducidos y analizados, por ejemplo, por Julio Seoane Pinilla (1998), Ángel Pelayo González-Torre (2006), María Concepción Pérez Pérez (2007), Oscar del Barco (Sade, 2010), Mauro Armiño (Sade, 2003; AA.VV., 2010), Lydia Vázquez Jimenez (2002; Sade, 2018) e Irene Aguilá-Solana (2016).

Actualmente, quienes se hacen eco de aquel esfuerzo que llevaron a cabo tales intelectuales del siglo XX por reconstruir un "sistema filosófico" sadeano, suelen estudiar la obra del conocido marqués de Sade a través de la mirilla filológico-historiadora que esta última camada de intérpretes nos lega. Aunque más no sea fragmentariamente, continuamos descubriendo en la obra esotérica ${ }^{2}$ sadeana un amplio crisol de propuestas filosóficas discutidas durante el Siglo de las Luces que aparecen allí reescritas, subvertidas y reutilizadas en función de justificar la equivalencia entre el vicio y la virtud, tal como constatamos en los aportes de Caroline Warman (2002), Clara Castro (2015), y Henry Martyn Lloyd (2018). En lo que respecta al dominio metafísico-cosmológico, si bien la mayoría de estos estudios se ha concentrado en analizar la apropiación que Sade realiza del materialismo ilustrado -moderno (Warman, 2002)- o antiguo (Castro, 2015), el tratamiento que reciben las filosofías inmaterialistas en la obra sadeana merecería, desde nuestro punto de vista, mayor atención. Nuestra hipótesis es que, lejos de desestimarlas sin más, Sade realizaría una apropiación crítica -irónica- de estas filosofías, para demostrar la supremacía del inmanentismo materialista ateo. En este artículo, nos abocaremos a examinar el caso del llamado "sistema del alma del mundo", concentrándonos en el personaje de Bandole de La Nouvelle Justine. En primer lugar, entonces, estudiaremos cómo Bayle y Fréret caracterizaban a tal sistema filosófico, en razón del impacto que estos materiales habrían tenido en el armado de estas novelas obscenas sadeanas. En segundo lugar, analizaremos cómo aparecen en la trama de La Nouvelle Justine ciertas imágenes conceptuales y ciertas nociones identitarias del sistema del alma del mundo, tal como se lo reconstruye durante el siglo dieciocho en Francia. Por último, reconsideraremos nuestros resultados y ofreceremos nuestras conclusiones.

\section{Bayle, Fréret: un spinozismo "figurado"}

Uno de los textos al parecer más consultados por Sade que se encontraba sobre su "petit bureau" en el catálogo de su biblioteca en Lacoste ${ }^{3}$ es el Dictionnaire Historique et Critique de Pierre Bayle (Bayle, 1740). Esta extensa obra proponía una lectura no secuencial que partía de una reconstrucción histórica y biográfica de ciertas figuras y ciertas corrientes de pensamiento filosóficas. En ella, Bayle reponía tanto las tesis de la figura en cuestión como las críticas que esta recibía, adoptando cierto "pirronismo" (Mori, 1999) al desarrollar su reconstrucción.

Para nutrir su ecléctica prosa filosófica, Sade a menudo consultaba obras de este estilo, especialmente para obtener información acerca de sistemas inmanentistas y materialistas como el spinozismo. Si bien a Spinoza se lo acusó de ateo muy tempranamente (Cudworth, [1678] 1837), esta interpretación iba, en principio, bastante más allá de la literalidad de los textos del propio autor. Así, se generó en torno a las ideas de Spinoza durante la segunda mitad del siglo XVII y particularmente durante el siglo XVIII una suerte de retorsión creativa "contagiosa" (Citton, 2007) que se plasma muy evidentemente en el Dictionnaire de Bayle, fuente insoslayable para comprender qué se entendía entonces por spinozismo.

En este sentido, uno de los criterios identitarios del spinozismo, de acuerdo con Bayle, es la defensa de la doctrina de la sustancia única y de la identidad entre Dios y el mundo. En el artículo sobre Spinoza de su Dictionnaire, Bayle distingue dos tipos de expresiones posibles de pensamiento spinozista a lo largo de la historia: la vertiente materia-

La distinción planteada por Michel Delon entre textos esotéricos y exotéricos dentro del corpus sadeano (Sade, 1990: ix-lviii) tiene como objetivo diferenciar entre los escritos clandestinos de Sade y sus obras "oficiales".

Véase Mothu (1995: 679 [426]). Mothu indica que el ejemplar que Sade poseía en ese entonces era el Extrait du Dictionnaire historique et critique realizado por d'Argens y Federico II de Prusia y que, no obstante, en una carta de 1791 habría solicitado a Gaufridy el envío del Dictionnaire para entonces completo. Incluimos referencias a ambas ediciones. 
lista y la "acosmista" o "idealista/nihilista". Si bien ofrece algunos ejemplos de la primera, desde su punto de vista, el pensamiento de Spinoza se identifica más claramente con el "sistema del alma del mundo", el cual asocia primeramente a los estoicos (quienes creían, no obstante, en una forma de divinidad providencial, a diferencia de Spinoza). Este dogma del alma del mundo habría encontrado adeptos en diversos territorios y culturas. Desde el punto de vista de Bayle, sus distintas variantes ofrecerían la imagen metafórica del mundo como un gran océano, en el cual flotarían botellas de agua. Estas representan a cada una de las almas de los seres vivos. La muerte se produciría cuando una de estas botellas se rompe (el cuerpo se corrompe y se destruye) y entonces el agua que esta contenía se une al mar que la rodeaba (el alma particular se une al alma del mundo).

Platón ${ }^{4}$ y Pitágoras son mencionados como candidatos plausibles. En la cultura hindú, esta doctrina tendría mucho arraigo, según Bayle, al igual que en la secta china Foe Kiao. En el primer caso, se refiere a la comunidad de pendets, quienes consideran que Dios, a quien llaman “Achar", es inmóvil e inmutable (Bayle, 1740, t. IV: 254; Bayle, 1780, t. II: 162; Bayle, 2010: 344). Achar produciría no solamente las almas sino los cuerpos (todo lo corpóreo) del universo, obteniéndolos de su propia sustancia como si fuese una araña que elabora y recoge su telaraña: "La création donc, disent ces Docteurs imaginaires, n'est autre chose qu'une extraction et extension que Dieu fait de sa propre substance, de ces rets qu'il tire comme de ses entrailles, de même que la destruction n'est autre chose qu'une reprise qu'il fait de cette divine substance, de ces divins rets dans lui-même" (Bayle, 1740, t. IV: 254; Bayle, 1780, t. II: 162) por eso que, desde su perspectiva, todo aquello que es múltiple, todo aquello que pertenece al mundo de los sentidos constituiría una ilusión, la mera apariencia de lo real, que es lo Uno o Dios.

En cuanto a la secta china a la que se refiere Bayle, este nos relata que habría habido un desdoblamiento entre su doctrina exotérica y la esotérica, esta última secreta y reservada para un reducido círculo íntimo. La primera, dirigida al "pueblo", consistía en resumidas cuentas en la creencia en una divinidad justa, que recompensa la virtud y castiga la desobediencia post-mortem. La segunda, en cambio, proclamaba que el vacío o la "nada real" (el término chino sería “Cum hiu”, según indica Bayle [Bayle, 1740, t. IV: 255; Bayle, 1780, t. II: 163; Bayle, 2010: 348]) constituye una única sustancia que contiene a todo aquello que existe; a la manera del agua, que se manifiesta como la nieve, el hielo o la lluvia, los seres particulares se distinguen de ella (y entre sí) debido a que adoptan o presentan diferentes figuras y cualidades. Se le agrega a ello que, según estos filósofos chinos, la perfección de la sustancia única viene dada por su inacción y reposo, es decir, que esta no tiene inteligencia, poder o virtud alguna.

Cada una de estas expresiones del sistema del alma del mundo hace, en su formulación, más o menos evidente el matiz "nihilista" que se desprendería del "idealismo" pitagórico-platónico (en el sentido de la atribución de irrealidad a los cuerpos y objetos individuales). Esto le permitirá a Bayle profundizar el paralelo entre tal idealismo y la filosofía de Spinoza, a la que atacará con una "objeción” que remarca justamente la irrealidad de los modos, denominada "acosmisme". En verdad, no se trata puntualmente de una objeción en donde se señale una contradicción del sistema de Spinoza sino más bien del gesto de mostrar que de este se sigue esta consecuencia "indeseable" o "ridícula". Por otro lado, según Bayle, las objeciones que se suelen utilizar contra quienes defienden el sistema del alma del mundo, principalmente contra Pitágoras 6 , son asimismo útiles contra Spinoza y denuncian las siguientes "falsedades": "1, que la Nature divine serait déchirée en pièces: 2, qu'elle serait malheureuse autant de fois que les hommes: 3 , que l'esprit humain n'ignorerait aucune chose, puis qu'il serait Dieu”' (Bayle, 1740, t. IV: 262; Bayle, 1780, t. II: 180)7.

Así, vemos que el "sistema del alma del mundo", al igual que lo que sucede con el spinozisme en general, admitía diversas expresiones que podían ser todas ellas diferentes entre sí, inclusive opuestas, si se considera que algunas tendían más bien hacia el materialismo y otras hacia el inmaterialismo. El marqués d'Argens ${ }^{8}$ lo muestra claramente en su obra La philosophie du bon sens. Este autor reitera el vínculo que ya había establecido Bayle previamente, entre el sistema del alma del mundo y el spinozismo, aduciendo que el amstelodano le habría dado una formulación moderna al mismo (d'Argens, 2002: 192).

Otro texto rico en alusiones al sistema del alma del mundo es la Lettre de Thrasybule à Leucippe $(1765)^{9}$ de Nicolas Fréret ${ }^{10}$, texto que, como indica Deprun (1970), fue utilizado en Histoire de Juliette, reescrito en los discursos de Mme Delbène. En la Lettre, nos encontramos con una epístola ficticia en la que el personaje de Trasíbulo intenta persuadir a Leucipa de no consagrar su vida a la religión. Situada a comienzos de la Era Cristiana en alguna provincia

\footnotetext{
$4 \quad$ Platón aparecería aquí debido a su ascendiente pitagórico y su defensa de la metempsicosis. Otro texto en donde se afirma que Platón y Pitágoras sostenían el sistema del alma del mundo es el manuscrito clandestino titulado Tratado de los tres impostores (Traité des trois imposteurs), en algunas versiones también llamado L'esprit de Spinoza (anónimo, 2007). Véase Mothu (1995: 680 [427, vol. I, IV]).

"La creación (...), dicen estos doctores imaginarios, no es más que una extracción o extensión que Dios hace de su propia substancia, de esas redes que él saca como de sus entrañas, y, a su vez, la destrucción no es más que una recuperación que hace de esa sustancia divina, de esas redes divinas en él mismo" (Bayle, 2010: 344).

Bayle cita algunos pasajes del De Natura Deorum de Cicerón. Por ejemplo, DND I 27: "Pitágoras, quien consideró que aquel espíritu del que parecía desprenderse el nuestro se extendía a través del mundo de la naturaleza en su conjunto, no vio que la divinidad resultaba desgarrada y despedazada a consecuencia de la segregación de los espíritus humanos, y que, cuando se trataba de espíritus desdichados -como acontecía en la mayoría de los casos-, resultaba que era desdichada una parte de ella, cosa que no puede darse" (Cicerón, 1999: 94).

"1, que la naturaleza divina sería desgarrada en piezas (partes); 2, que ella sería desgraciada tantas veces como los hombres; 3, que el espíritu humano no ignoraría cosa alguna, puesto que sería Dios" (Bayle, 2010: 372).

En Histoire de Juliette (Sade, 1998: 519), la protagonista identifica al marqués d'Argens como el autor de la novela Thérèse philosophe, encomiándolo tibiamente. Véase Mothu (1995, 679 [427, vol. I, II]).

Véase Mothu (1995: 680 [427, vol. II, VII]).

10 La atribución a Fréret está presente en numerosos manuscritos de la obra, así como en sus versiones impresas y además ha sido refrendada por estudiosos como Sergio Landucci (1986), aunque discutida por Miguel Benítez (2013). Su redacción suele situarse aproximadamente en el año 1722. Fréret fue un dedicado historiador de las culturas y la filosofía antiguas (tal como se plasma en sus Mémoires académiques).
} 
del Imperio Romano, la Lettre ofrece un análisis histórico de las diferentes religiones de los antiguos, las cuales se dividen allí entre politeístas (egipcios, hindúes, griegos, romanos) y monoteístas (judíos, caldeos, cristianos, árabes, persas).

Refiriéndose a "los hindúes", Trasíbulo reporta que sus dogmas filosóficos esotéricos parten de la concepción de la indistinción entre la sustancia divina y el universo, por lo que nuestros cuerpos y nuestras almas serían partes o modificaciones de esta. Este personaje parecería inclinarse hacia un escepticismo o agnosticismo sobre la noción de Dios; sin embargo, en algunos pasajes especula lúdicamente con una cosmovisión spinoziste, a la que destaca como la más cercana a sus opiniones. En efecto, imaginando un sistema de pensamiento al que le gustaría adherir, Trasíbulo asevera:

Si je voulais faire un Système, $\mathrm{j}$ 'aimerais encore mieux dire que tout ce qui existe, existe nécessairement, a toujours existé et existera toujours, et qu'il ne peut pas ne point exister; que ses divers changements apparents ne sont tels que par rapport à nous et aux impressions que font sur nous les êtres qui nous touchent; que, selon les divers aspects dont nous l'envisageons, nous disons qu'il passe d'une modification à l'autre, qu'il acquiert et qu'il perd des propriétés; que cependant, non seulement sa force d'exister ou son existence, incapable d'accroissement et de diminution, est toujours la même, mais que le changements que nous croyons voir dans ses propriétés n'ont pas plus de réalité que ceux de ces objets dont la forme et la couleur changent suivant le point de vue dont nous les envisageons (Mori \& Mothu [Comp.], 2010: 144) $)^{11}$.

Aquí Trasíbulo imagina, en primer lugar, una cosmovisión que postula la eternidad de aquello que existe (curiosamente no se limitaría a lo material sino que parecería preservarse el ímpetu sustancialista de Spinoza), describiéndolo como un todo, cuyos cambios serían aparentes y relativos al punto de vista que adoptemos para examinarlos (lo que en el pasaje se afirma metafórica y literalmente en el ejemplo de los posibles efectos de la luz sobre los colores que percibimos). Se utiliza el término "modification" para designar estas transformaciones, las cuales no afectarían a la "fuerza de existir" del todo, que no puede ni crecer ni disminuir. Por un lado, Trasíbulo parecería apropiarse de ese "acosmisme" que Bayle denostaba como una de las consecuencias indeseables del pensamiento de Spinoza y resignificarlo, adoptándolo para sí. A continuación, examinaremos cómo retoma Sade todas estas concepciones y figuraciones del sistema del alma del mundo, concentrándonos en una figura puntual de La Nouvelle Justine: Bandole.

\section{Bandole}

La composición del personaje sadeano con el que trabajaremos, M. de Bandole, evoca el rico imaginario en torno a dicho sistema, particularmente en su arista pitagórico-platónica. Este antiguo parlamentario, dueño de un amplio castillo que se encontraba en el medio de un bosque, solía secuestrar mujeres encerrándolas allí, para violarlas con el propósito de embarazarlas. Contaba con diversos mecanismos que le garantizaban el éxito, en este sentido. En principio, había diseñado artefactos que le facilitaban la tarea de la "impregnación": uno de ellos inmovilizaba a la víctima, disponiéndola para la penetración y otro sujetaba sus piernas por encima de su cabeza, posteriormente al acto, para que el semen no escapara de su cuerpo. Luego, obligaba a estas mujeres a llevar a término su embarazo para que cuando naciese el bebé, a la edad de 18 meses, él pudiese ahogarlo en un estanque cercano.

En principio, cabe recordar aquí una de las metáforas con las que se expresaba el sistema del alma del mundo: aquella según la cual en un gran océano flotaban todas las botellas de agua o almas particulares. En este sentido, el estanque se convertía, a causa de las acciones de Bandole, en el "cercueil universel" de dichos bebés (Sade, 1995: 574). La pequeñez del estanque, al compararla con el inmenso océano figurado, remarca la insignificancia irrisoria del individuo libertino en relación con la naturaleza, y a su vez la distancia conceptual que existe entre ellos, perteneciendo él al ámbito de la literalidad, ella al de la metáfora. Además, se trata de agua estancada, detenida, lo que nos ofrece una imagen bastante "decadente" de la naturaleza libertina, que es en realidad movimiento incesante. Este "homenaje" (los asesinatos que comete) que Bandole se esfuerza por reproducir una y otra vez consistiría en intentar aumentar el caudal de esa alma universal, nutriéndola de los "frutos"'2 (Ibid.) que él mismo cosecha.

Luego de que Bandole "examine" los genitales de Justine para saber si está "bien constituida" como para llevar a término un embarazo, la muchacha le reprocha su falta de humanidad. Se da un breve intercambio entre ellos a propósito de esta "virtud" y el libertino, complacido por la sagacidad de Justine, pide quedarse a solas con ella para discutir más extensamente el tema:

\footnotetext{
"Si yo quisiera hacer un sistema, me gustaría incluso más decir que todo aquello que existe, existe necesariamente, que ha existido siempre y que existirá siempre y que no puede no existir; que sus diversos cambios aparentes no son tales sino en relación con nosotros y con las impresiones que realizan sobre nosotros los seres que nos tocan; que, según los diversos aspectos a partir de los cuales lo proyectamos, decimos que pasa de una modificación a otra, que adquiere y pierde propiedades; que sin embargo, no solamente su fuerza de existir o su existencia, incapaz de acrecentamiento o disminución, es siempre la misma, sino que los cambios que creemos ver en sus propiedades no tienen más realidad que aquellos de los objetos cuya forma y color cambian de acuerdo al punto de vista desde el cual los imaginamos". La traducción es propia, como en todos aquellos casos en los que no se indica referencia bibliográfica a una traducción ya publicada.

12 En efecto, otro de los rasgos identitarios de Bandole es su estricto vegetarianismo, el cual es una característica típicamente atribuida a Pitágoras,
} quien prohibía la matanza de animales para su consumo. 
Il [Bandole] lui prouva (...) qu'il n'y avait aucune espèce de mal à disposer du fruit qu'on avait planté, et que nous n'avions sur aucune propriété des droits mieux fondés que sur cela.

- L'intention de la nature est remplie, dès que la femme est enceinte, poursuivit Bandole ; mais il lui est égal que le fruit mûrisse où qu'il soit cueilli dans sa verdeur.

- Oh ! monsieur, vous ne tirerez jamais de justes comparaisons de la chose inanimée à l'être possédant une âme.

- Une âme ? dit Bandole, en éclatant de rire ; ah ! dis-moi, je t'en prie, ma chère, ce que tu entends par cette expression.

- Elle me donne l'idée du principe vivifiant et éternel, sublime et grande émanation de la Divinité, qui nous rapproche d'elle, qui nous unit à elle, et qui, par la perfection de son essence, nous distingue de tous les animaux (Sade, 1995 : $579)^{13}$.

Bandole parte de la indiferencia entre lo vivo y lo muerto. La naturaleza, según este personaje, acoge todo tipo de formas. Justine no acepta dicha equivalencia, dado que supone que el alma distingue cualitativamente a los seres humanos de todas las demás criaturas. La ecléctica definición que esboza Justine implica, entre otros matices, la concepción del alma como hálito vital (que podríamos trazar hasta Homero). Esta caracterización se ensambla a su vez con la idea de que el alma es un principio vivificador que "emana" de la divinidad y que, tal como afirma la joven, "nos une a ella".

Para comprender el uso que Justine hace aquí del término “emanación”, proponemos tener en cuenta el comentario del abad Nicolas-Sylvestre Bergier en la entrada "Âme" del tomo sobre Teología que redacta para la llamada "Encyclopédie Panckoucke" o "Encyclopédie méthodique"14, la cual se proponía continuar y ampliar l'Encyclopédie de Diderot y D’Alembert. Bergier era un apologista de la religión, un intelectual contrailustrado muy prolífico cuyas obras Sade gustaba de leer ${ }^{15}$. Allí, el abad sostiene lo siguiente: “Quant au système de l'émanation des âmes hors de la substance de Dieu, ç’a été celui des Philosophes, et non des Docteurs de l'Église, qui tous ont admis la création” (Bergier, 1788: 58 $)^{16}$. Añade a continuación que han sido ciertos "críticos protestantes" los que han instalado el término "émanation", utilizándolo para caracterizar la posición de Platón (y de algunos neoplatónicos posteriores) respecto de cómo se producía el noûs (o la mens). La emanación no implicaba, sin embargo, que la sustancia divina no fuese simple e indivisible; al emanar de ella los espíritus, no se producía en dicha sustancia divina ninguna disminución o partición. Lo mismo ocurría respecto de la emanación del mundo.

Difícilmente podríamos interpretar que el uso del término "émanation" por parte de Justine responda simplemente a cierta falta de delicadeza, si bien debemos admitir cierto eclecticismo de su pensamiento, que vemos concentrado aquí, por ejemplo, en su definición de alma. Examinando los comentarios de los personajes libertinos sobre las capacidades intelectuales de Justine, notamos que esta joven está muy bien ponderada como pensadora. Sin embargo, el mismo Bergier remarca que "Les Athées modernes et les Matérialistes, afin de tourner notre croyance en ridicule, ont dit que, sous le nom de Dieu, nous n'entendons rien autre chose que l'âme du monde ${ }^{17}$, ou l'univers animé" (Bergier, 1788: 58 ${ }^{18}$. De manera que a través de este vocabulario teológico-filosófico de alto grado de abstracción que emplea Justine, el autor de La Nouvelle Justine podría estar ridiculizando a la cosmovisión (neo)platónica fundante del Cristianismo que expresa esta joven.

Et ici Bandole, ayant éclaté de rire une seconde fois, dit à Justine :

- Écoute, mon enfant ; je m'aperçois que tu as quelque mérite, et je veux bien consentir à t'éclairer, un peu d'attention, et suis-moi. Il n'est rien d'aussi absurde, sans doute, que le système des gens qui s'acharnent à dire que l'âme est une subs-

13 “[Bandole] le probó [a Justine] (...) que no había ninguna especie de mal en disponer del fruto que uno había plantado, y que no teníamos sobre propiedad alguna derechos mejores fundados que sobre esta.

- La intención de la naturaleza se cumple, desde que la mujer está embarazada, continuó Bandole; pero le es igual que el fruto madure o que sea recogido [cuando todavía está] en su verdor.

- ¡Oh! Señor, no obtendrá jamás comparaciones justas (precisas) [yendo] de la cosa inanimada al ser que posee un alma.

- ¿Un alma? Dice Bandole estallando de risa; ¡ah! Dime, te lo ruego, mi querida, lo que entiendes por esta expresión.

- Me da la idea del principio vivificante y eterno, sublime y gran emanación de la divinidad, que nos acerca a ella, que nos une a ella, y que, por la perfección de su esencia, nos distingue de todos los animales".

14 Fue organizada y editada por Charles-Joseph Panckoucke desde 1782 hasta 1798, año de su fallecimiento, labor posteriormente continuada por su socio Henri Agasse y, luego de morir este, por su esposa Antoinette-Pauline Agasse, completándose en 1832. Su título era L'Encyclopédie méthodique ou par ordre de matières par une société de gens de lettres, de savants et d'artistes; précédée d'un Vocabulaire universel, servant de Table pour tout l'Ouvrage, ornée des Portraits de MM. Diderot et d'Alembert, premiers Éditeurs de l'Encyclopédie.

15 En una carta datada el 23-4 de noviembre de 1783, escrita por Sade desde la prisión de Vincennes, este le pide a su esposa que le envíe un ejemplar del Sistema de la naturaleza de d'Holbach para poder apreciar mejor su refutación. Sade se refiere a L'examen du matérialisme ou réfutation du Système de la nature del abad Bergier (Sade, 1966, t. XII: 416). Para profundizar en la relación Sade-Bergier, véase Abramovici (2017).

16 "En cuanto al sistema de la emanación de las almas fuera de la sustancia de Dios, ha sido el de los Filósofos, y no el de los Doctores de la Iglesia, quienes han admitido todos ellos la creación".

17 “ÂME DU MONDE. Le système de Pythagore, des Stö̈ciens et d'autres Philosophes, était que le monde est un grand tout dont Dieu est l'âme, et duquel les différents corps, comme les astres, la terre, la mer, etc. sont les membres ; que Dieu est répandu dans toutes ces parties et les anime, comme notre âme vivifie et fait mouvoir toutes les parties de notre corps. Cette opinion supposait que la matière est éternelle, que Dieu ne l'a point créée, mais seulement arrangée, et qu'il a ainsi formé son propre corps, qui est le monde" (Bergier, 1788: 58).

En español: "ALMA DEL MUNDO. El sistema de Pitágoras, de los Estoicos y de otros Filósofos, era que el mundo es un gran todo del cual Dios es el alma, y cuyos miembros son los diferentes cuerpos, como los astros, la tierra, la mar, etc.; que Dios está extendido en todas estas partes y las anima, como nuestra alma vivifica y hace mover todas las partes de nuestro cuerpo. Esta opinión supondría que la materia es eterna, que Dios no la ha creado, sino solamente organizado y que ha así formado su propio cuerpo, que es el mundo".

18 "Los ateos modernos y los materialistas, a fin de volver ridícula nuestra creencia, han dicho que, bajo el nombre de Dios, no entendemos otra cosa que el alma del mundo o el universo animado". 
tance différente du corps (...). Ils ont fait de la partie qu'ils ont nommée ÂME une substance isolée, et lui ont accordé le droit imaginaire de penser abstractivement de la matière dont elle émane uniquement (...). Eh ! non, Justine, non; ne croyons pas que notre âme puisse agir d'elle-même ou sans cause, dans aucun des instants de notre vie : absolument liée aux éléments matériels qui composent notre existence, entièrement dépendante d'eux, toujours soumise aux impressions des êtres qui agissent en nous nécessairement, et d'après leurs propriétés, les mouvements secrets de ce principe, vulgairement appelé ÂME, sont dus à des causes cachées au-dedans de nous-mêmes [de notre corps] (Sade, 1995: 579-580) ${ }^{19}$.

Partiendo de la diferenciación entre el alma y el cuerpo (según Bandole, aquella no sería sino una parte de este), hubo quienes procuraron aislar conceptualmente la primera (ilegítimamente, desde el punto de vista del libertino) como si esta fuese una sustancia realmente distinta del cuerpo que podría subsistir sin él. Bandole se aprovecha aquí de la presunta "vulnerabilidad teórica" de Justine, quien al utilizar el vocabulario emanativo, queda expuesta a una posible identificación de su propia postura con el spinozisme ${ }^{20}$ y con el sistema del alma del mundo. Bandole entonces recupera el verbo "emanar", aplicándolo para explicar la naturaleza corpórea del alma, la cual provendría o "emanaría" de la materia ${ }^{21}$.

En efecto, el libertino redefiniría el concepto de "alma" virando la discusión hacia su aspecto gnoseológico: el alma es siempre "sumisa a las impresiones" que recibimos de otros cuerpos que impactan sobre el nuestro. Parecería evocarse así la dimensión consciente del sujeto perceptivo, que dependería de causas puramente materiales. De hecho, se sugiere en el pasaje que ciertos procesos "secretos escondidos dentro de nosotros mismos" son los que originan la actividad del alma. Nos permitimos agregar la aclaración de que se trata de procesos de los órganos internos del cuerpo, puesto que este fragmento del discurso de Bandole parecería estar inspirado en el Sistema de la naturaleza (I, VI) de d'Holbach (d'Holbach, 1990, 1982). Allí, el barón distingue entre dos tipos de movimientos posibles respecto de los seres humanos: unos son los movimientos de masa por los que el cuerpo entero o algunas de sus partes son visiblemente trasladadas de un lugar a otro; los otros son movimientos internos y ocultos de los cuales algunos son perceptibles para nosotros, mientras que otros se efectúan sin que nos demos cuenta y no se dejan adivinar más que por los efectos que producen afuera.

El desconocimiento de estos movimientos o mecanismos no evidentes llevó al ser humano, según d'Holbach, a creer que contenía en sí mismo un principio motor, distinto de su cuerpo, que se movía por su propia energía y actuaba siguiendo leyes totalmente diferentes de las que regulan los movimientos de los objetos. Ha juzgado no solamente que este principio motor era un ser aparte, sino también que tenía una naturaleza diferente de todos los seres de la Naturaleza, una esencia más simple. De ahí han derivado, sucesivamente, las nociones de espiritualidad, de inmaterialidad, de inmortalidad y todas las palabras "vagas" que, desde el punto de vista del barón, se han inventado a fuerza de sutilezas, para subrayar los atributos de esta sustancia desconocida que el hombre creía contener en sí mismo y que juzgaba ser el principio oculto de sus acciones visibles. Por último, este supuso que su alma, dado que era inmaterial, no estaría sujeta a la corrupción natural y que por tanto no perecería jamás, satisfaciendo su deseo de inmortalidad y aplacando su angustia ante la inminencia de la muerte.

Les imbéciles, après avoir fait de cette âme qu'ils fabriquaient à leur guise un être simple, inétendu, dépourvu de parties, absolument différent, en un mot, de tout ce que nous connaissons, prétendirent qu'elle n'était point sujette aux lois que nous trouvons dans tous les êtres dont l'expérience nous montre la décomposition perpétuelle; ils partirent de ces faux principes pour se persuader que le monde avait aussi une âme spirituelle, universelle, et ils donnèrent le nom de Dieu à cette nouvelle chimère dont celle de leur corps devenait une émanation. De là, les religions, et toutes les fables absurdes qui en découlèrent, tous les systèmes gigantesques et fabuleux qui devaient nécessairement résulter de cette première

19 "Y aquí Bandole, habiendo estallado de risa una segunda vez, dice a Justine:

- Escucha, mi niña; percibo que tienes [como pensadora] algún mérito, y quiero contribuir a iluminarte, un poco de atención y sígueme. No hay nada tan absurdo, sin duda, como el sistema de las personas que se obstinan en decir que el alma es una sustancia diferente del cuerpo (...). Han hecho de la parte que han nombrado ALMA una sustancia aislada, y le han acordado el derecho imaginario de pensar abstractamente [respecto] de la materia de donde ella emana únicamente (...). ¡Eh! No, Justine, no; no creamos que nuestra alma pueda actuar por sí misma o sin causa, en ningún instante de nuestra vida: absolutamente ligada a los elementos materiales que componen nuestra existencia, enteramente dependiente de ellos, siempre sumisa a las impresiones de los seres que actúan en nosotros necesariamente, y según sus propiedades, los movimientos secretos de este principio, vulgarmente llamado ALMA, se deben a causas escondidas dentro de nosotros mismos [de nuestro cuerpo]".

20 Más allá de lo que hemos visto en el Dictionnaire de Bayle, Bergier por su parte apoya la idea de una cercanía entre el sistema del alma del mundo, al cual se vincula típicamente la terminología emanativa, y el spinozisme: "Dans celle [1'hypothèse] de Pythagore et des Stoïciens, on ne conçoit pas mieux la spiritualité des âmes que celle de Dieu; toutes sont des parties de la grande âme, de laquelle elles ont été détachées, et de laquelle elles sont sorties par émanation, à laquelle elles doivent se réunir et s'y confondre, comme une goutte d'eau qui retombe dans l'océan. Les esprits ontils donc des parties? Beausobre emploie inutilement toute son industrie pour sauver encore cette absurdité. Il peut avoir raison de soutenir que ce n'est point là le spinosisme, mais c'est du moins une erreur qui en approche beaucoup" (Bergier, 1788: 58). Beausobre es uno de los historiadores o críticos protestantes que mencionábamos anteriormente.

En español: "En esta [hipótesis] de Pitágoras y de los Estoicos, no se concibe mejor la espiritualidad de las almas que la de Dios; todas son partes de la gran alma, de la cual ellas han sido desprendidas, y de la que han salido por emanación, con la cual deben reunirse y confundirse, como una gota de agua que cae sobre el océano. ¿Los espíritus son entonces partes? Beausobre emplea inútilmente toda su industria para salvar todavía esta absurdidad. Puede tener razón al sostener que no es eso el spinozismo, pero es al menos un error que se le aproxima mucho".

21 Aram Vartanian (1982) argumenta que, en el proceso de materialización del alma que se dio durante la primera mitad del siglo XVIII, dos modelos conceptuales de esta entraron en tensión. El primero, de inspiración epicúrea, presentaba al alma como un conjunto de partículas sutiles provenientes del Sol. El segundo la describía como una función surgida de determinadas estructuras fisiológicas. Si bien este segundo modelo estaba inspirado en el mecanicismo cartesiano, se fundaba en el rechazo al dualismo sustancialista de Descartes. Según Vartanian, este último modelo es el que prevalecerá, lo que puede constatarse en la obra de La Mettrie, Diderot y d’Holbach. En el caso de Bandole, indicaremos a continuación cómo su perspectiva materialista acerca del alma parece estar en sintonía con la del autor del Système de la nature. 
extravagance: de là, les idées romanesques de peines, des récompenses après cette vie: absurdité la plus révoltante de toutes; car, si l'âme humaine était une émanation de l'âme universelle, c'est-à-dire, du Dieu de l'univers; comment pouvait-elle mériter ou démériter? comment, perpétuellement enchaînée à l'être dont elle émanait, pouvait-elle être libre? et, d'après cela punie ou récompensée comme telle? (Sade, $1995: 581)^{22}$.

Quienes hipostasiaron el alma, creando conceptualmente una entidad "quimérica", han desestimado la "experiencia", es decir, la observación del mundo natural. Según Bandole, esta nos confirma la "descomposición perpetua" de los seres. Pero es este mismo conjunto de "imbéciles" el que, apoyándose en su "fabricación” de la noción de alma como algo realmente distinto del cuerpo, extendió este procedimiento al mundo, postulando la existencia de un alma espiritual universal. La denominaron "Dios", y supusieron que de ella "emanaban" sus propios cuerpos. Bandole critica aquí la versión inmaterialista del sistema del alma del mundo, culturalmente vinculada al pitagorismo y a su defensa de la metempsicosis o transmigración de las almas en distintos cuerpos (que van de esta manera viviendo distintas vidas). Según el libertino, de este sistema de pensamiento surgen "las religiones" y, particularmente, la idea de los premios y castigos post mortem, el cielo y el infierno -todas nociones que para un materialista resultan absurdas y "fabulosas".

\section{Conclusión}

Las novelas libertinas de Sade están plagadas de discursos filosóficos materialistas ateos que transmiten las proclamas y nociones clave del ala más radical de la Ilustración. Como hemos intentado mostrar, la circulación de los saberes adquirió durante el Siglo de las Luces un dinamismo inusitado que daba lugar, en muchos casos, a una escritura profusamente intertextual ${ }^{23}$, tal como puede constatarse en las ficciones de Sade. Similarmente, las obras de estilo recopilatorio que estudian y reconstruyen históricamente los distintos sistemas de pensamiento, como aquellas de Bayle, d'Argens y Fréret, no son meras reproducciones sin más, sino que se evidencia en ellas un fuerte trabajo de organización y (re)composición intelectual. Estas intervenciones frecuentemente aúnan bajo un mismo hilo conductor filosofías que surgieron en coordinadas espacio-temporales radicalmente distintas. Así, el esfuerzo de estos autores por comprender las distintas expresiones de (lo que ellos consideran) una misma matriz filosófica da como resultado la creación o la consolidación de constructos historiográficos eclécticos, como sucede en el caso del spinozismo y del sistema del alma del mundo.

De manera que, como remarcamos al comienzo, en las ficciones esotéricas de Sade, sus personajes libertinos esbozan discursos materialistas y ateos. Para justificar sus crímenes, proponen concebir a la Naturaleza como si esta fuese indiferente ante la moralidad o la inmoralidad de las acciones de sus criaturas. Tal como explica Julio Seoane Pinilla, para Sade "la Naturaleza a la que la Ilustración acude cuando destrona al Rey y se queda sin Dios no es la expresión laica de los anteriores códigos" (1998: 77). En efecto, dentro de las comunidades libertinas sadeanas se suele negar mayoritariamente la existencia de dios o de una entidad normativa que pueda legítimamente establecer un código de conducta obligatorio universal. Pero Sade también se encarga de ridiculizar, a través de las disertaciones de estos personajes, a los sistemas filosóficos que adolecen de atavismos religiosos. En efecto, la figura de Justine resulta sumamente importante en este sentido, ya que suele expresar muchas de las objeciones y de los contra-argumentos que se esgrimían para refutar al materialismo ateo en aquel entonces.

Esta complejidad dialógica que propone Sade, a partir de la cual se debaten en el marco de sus ficciones distintas tesis metafísicas, nos lleva a preguntarnos si efectivamente existe o no un único sistema filosófico sadeano. Tal como afirma María Concepción Pérez Pérez, “desde el punto de vista filosófico, Sade no construye sistemas, pero sí parodia y destruye la filosofía optimista de las Luces" (2007: 49). Ahora bien, para analizar esta parodia, debemos desdoblarla en al menos dos dimensiones. En primer lugar, los personajes libertinos sadeanos defienden afirmativamente distintas expresiones del materialismo ilustrado, al cual, a su vez, sexualizan, vulgarizan y representan como una filosofía amoral e inmoral de la que se sirven para reivindicar sus crímenes. Si Sade se detuviese allí, podría deducirse, a partir de su gesto paródico, cierta ambigüedad en su compromiso con el movimiento ilustrado. Por un lado, parecería querer difundir las ideas materialistas pero, por otro lado, en sus ficciones, Sade buscaría atribuirles a tales intelectuales materialistas un extremo grado de villanía y crueldad. Planteando la tensión de la parodia sadeana de esta manera, podríamos argumentar tanto que Sade actúa como un ilustrado radical como que se comporta como un contra-ilustrado. En este segundo caso, Sade buscaría reafirmar la acusación que sostenían los apologistas de la religión y e intelectuales más conservadores como Bergier, de que el materialismo ateo conduce al libertinaje de costumbres, luego, al crimen y, por último, a la extinción de toda la especie.

\footnotetext{
22 "Los imbéciles, después de haber hecho de este alma que fabricaban a su gusto un ser simple, inextenso, desprovisto de partes, absolutamente diferente, en una palabra, de todo eso que [ya] conocemos, pretendieron que no estaba sujeta a las leyes que encontramos en todos los seres cuya descomposición perpetua nos muestra la experiencia; partieron de estos falsos principios para persuadirse de que el mundo tenía también un alma espiritual, universal, y dieron el nombre de Dios a esta nueva quimera, de la cual aquella [el alma] de su cuerpo se tornaba una emanación. De allí, las religiones, y todas las fábulas absurdas que de ellas se derivan, todos los sistemas gigantescos y fabulosos que debían necesariamente resultar de esta primera extravagancia: de allí, las ideas novelescas de penas, de recompensas después de esta vida: la absurdidad más indignante de todas; pues, si el alma humana era una emanación del alma universal, es decir, del Dios del universo; ¿cómo podía ella tener mérito o demérito alguno? ¿Cómo, perpetuamente encadenada al ser del cual emanaba, podía ser libre? Y, ¿de acuerdo con ello castigada o recompensada como tal?”.

23 Véase McKenna (2005: 22) y Genette (1989).
} 
Sin embargo, en segundo lugar, Sade decide replicar las distintas aristas de la crítica materialista a las religiones y las filosofías teístas y deístas que encuentra en los textos ilustrados, tal como hemos constatado. Si Sade quisiese destruir la reputación del ala más intransigente del movimiento iluminista para intervenir en la esfera ideológico-cultural en favor del conservadurismo, ¿para qué se molestaría en difundir las demoledoras argumentaciones en contra de aquellos valores que en realidad buscaría defender? Desde nuestro punto de vista, la crítica que realiza Bandole al sistema del alma del mundo pone de manifiesto su voluntad por demostrar que el materialismo no solamente es más coherente que el inmaterialismo sino que además parecería ser, de las dos, la posición filosófica más originaria -lo que haría del inmaterialismo una suerte de "degeneración conceptual”. Ponderando la hipótesis que interpreta a Sade como un contra-ilustrado, nos preguntamos: ¿acaso no lleva el marqués la parodia demasiado lejos como para que se lo considere un enemigo tradicionalista del movimiento ilustrado?

\section{Referencias bibliográficas}

\section{Obras de Sade}

Sade, D. A. F., (1990 ; 1995 ; 1998) Euvres, t. I-III. Introducción y notas de M. Delon. París, Gallimard-Pléiade.

Sade, D. A. F., (1987) CEuvres complètes, t. I-XV. Edición de J. J. Pauvert. París, Fonds Pauvert.

Sade, D. A. F., (1966) Euvres complètes, t. I-VII. Edición de G. Lely. París, Le Cercle du Livre Précieux.

\section{Bibliografía complementaria:}

AA. VV., (2010) Cuentos y Relatos Libertinos. Traducción, introducción y edición de M. Armiño. Buenos Aires, FCE.

Abramovici, J.-C., (2017) "Sade antiphilosophe" in Dictionnaire des anti-Lumières et des antiphilosophes. París, Honoré Champion, pp. 1413-6.

Adorno, T., \& M. Horkheimer, (1998) Dialéctica de la Ilustración. Madrid, Trotta.

Anónimo, (2007) Tratado de los tres impostores. Traducción, introducción y notas de D. Tatián. Buenos Aires, El cuenco de plata. Apollinaire, G., (1909) L'Euvre du Marquis de Sade. París, Bibliothèque des curieux.

Barthes, R., (1971) Sade, Fourier, Loyola. París, Éditions du Seuil.

Bataille, G., (1990) La litérature et le mal: Emily Brontë, Baudelaire, Michelet, Blake, Sade, Proust, Kafka, Genet. París, Folio Essais.

Bataille, G., (2011) L'érotisme. París, Minuit.

Bayle, P., (1740) "Spinoza” in Dictionnaire historique et critique (5ta edición) [En línea]. Amsterdam, Leyde, La Haye, Utrecht. Versión online provista por The ARTFL Project : http://artflsrv02.uchicago.edu/cgi-bin/dicos/baylepublic.pl?headword=Spinoza\&pagetag $=$ [Último acceso el 22 de septiembre de 2020].

Bayle, P., (1780) "Spinoza" in Extrait du Dictionnaire historique et critique. 2 tomos. Edición de Federico II de Prusia y el marqués d'Argens. Amsterdam, Casa de edición no declarada.

Bayle, P., (2010) Diccionario Histórico y Crítico. Selección. Introducción, traducción y notas de F. Bahr. Buenos Aires, El cuenco de plata.

Beauvoir, S. de, (1972) Faut-il brûler Sade? París, Gallimard.

Benítez Rodríguez, M., (2013) Le Foyer clandestin des Lumières: Nouvelles recherches sur les manuscrits clandestins. París, Honoré Champion.

Bergier, N. S., (1771) L'examen du matérialisme ou réfutation du Système de la nature. París, Chez Humblot.

Bergier, N. S., (1788) Encyclopédie Méthodique, par ordre de matières; par une société de gens de lettres, de savans et d'artistes. Théologie (t. I). París, chez Panckoucke.

Blanchot, M., (1949) Lautréamont et Sade. París, Minuit.

Camus, A., (1957) L’homme revolté. París, Gallimard.

Castro, C., (2015) Os Libertinos de Sade. São Paulo, Iluminuras.

Cicerón, M. T., (1999) Sobre la naturaleza de los dioses. Introducción, traducción y notas de A. Escobar. Madrid, Gredos.

Citton, Y., (2007) "L'invention du spinozisme dans la France du XVIII siècle” in Secrétan, C., Dagron, T. \& L. Bove (dir.), Qu'est-ce que les Lumières "radicales "? Libertinage, athéisme et spinozisme dans le tournant philosophique de l $\square$ âge classique. París, Éditions Amsterdam.

Cudworth, R., [1678] (1837) The true intellectual system of the universe: wherein all the reason and philosophy of atheism is confuted, and its impossibility demonstrated. New York, Gould \& Newman.

D’Argens, J. B. Boyer, (2002) La Philosophie du bon sens, ou Réflexions philosophiques Sur l’incertitude des connaissances humaines, à l'usage des cavaliers et du beau sexe. Edición de G. Pigeard de Gurbert. París, Honoré Champion.

D’Holbach, P. H. T., (1990) Système de la nature ou des lois du monde physique et du monde moral. Edición de J. Boulad-Ayoub. París, Fayard.

D’Holbach, P. H. T., (1982) Sistema de la naturaleza. Traducción y notas de J. M. Bermudo. Madrid, Editora nacional.

Deleuze, G., (1967) Présentation de Sacher-Masoch. Paris, Minuit. 
Deprun, J., (1970) “Quand Sade récrit Fréret, Voltaire et d'Holbach” in Roman et Lumières au XVIII siècle. París, Éditions Sociales, pp. 331-40.

Deprun, J., (1976) “La Mettrie et l'immoralisme sadien” in Annales de Bretagne et des pays de l'Ouest. Vol. 83, n 4, pp. 745-750.

Deprun, J., (1980) "Sade et le rationalisme des Lumières” in Raison présente. Vol. 55, pp. 17-29.

Foucault, M., (1990) Les Mots et les choses. París, Gallimard.

Foucault, M., (1994) Histoire de la sexualité, I: La volonté de savoir. París, Gallimard.

Foucault, M., (1999) Les anormaux: cours au Collège de France: 1974-1975. París, Gallimard.

Foucault, M., (2013) La grande étrangère. A propos de littérature. París, EHESS.

Fréret, N., (1986) Lettre de Thrasybule à Leucippe. Edición de S. Landucci. Florencia, L. S. Olschki.

Genette, G., (1989) Palimpsestos. La literatura en segundo grado. Traducción de C. Fernández Prieto. Madrid, Taurus.

González-Torre, A., (2006) La sombra de la Ilustración. Tres variaciones sobre Sade. Santander, Servicio de publicaciones de la Universidad de Cantabria.

Klossowski, P., (1967) Sade mon prochain. Paris, Éditions du Seuil.

Laborde, A., (1974) Sade romancier. Neuchâtel, La Baconnière.

Le Brun, A., (1993) Soudain un bloc d'abîme, Sade. París, Gallimard.

Lloyd, H. M., (2018) Sade's philosophical system in his Enlightenment context. Switzerland, Palgrave Macmillan.

McKenna, A., (2005) "Les manuscrits philosophiques à l'Âge classique: bilan et perspectives des recherches" in Lettres de Versailles. Porto, Universidade do Porto, pp. 11-26.

Mori, G. \& A. Mothu (Comp.), (2010) Philosophes sans Dieu. Textes athées clandestins du XVIII siècle. París, Honoré Champion.

Mori, G., (1999) Bayle philosophe. París, Honoré Champion.

Mothu, A., (1995) "La bibliothèque de Sade à Lacoste" in Lever, M., Papiers de famille 2. Le marquis de Sade et les siens (17611815). París, Fayard, pp. 595-711.

Pérez Pérez, M. C., (2007) Sade. Madrid, Síntesis.

Roger, P. (1976). Sade. La philosophie dans le pressoir. París, Grasset.

Sade, D. A. F., (2003) La nueva Justine o las desgracias de la virtud. Traducción M. Armiño. Madrid, Valdemar.

Sade, D. A. F., (2010) La filosofía en el tocador. Traducción, Introducción y notas de O. del Barco. Buenos Aires, Colihue.

Sade, D. A. F., (2018) Mi gran carta. Traducción de L. Vázquez Jimenez. Madrid, ADE Teatro.

Seoane Pinilla, J., (1998) La ilustración heterodoxa: Sade, Mandeville y Hamann. Madrid, Fundamentos.

Vartanian, A., (1982) “Quelques réflexions sur le concept d’âme dans la littérature clandestine” in Bloch, O. (dir), Le matérialisme du XVIII siècle et la littérature clandestine. París, Vrin, pp. 149-165.

Vázquez Jimenez, L., (2002) “Sade en español” in Barcarola. No 61-62, pp. 257-267.

Warman, C., (2002) Sade: From Materialism to Pornography. Oxford, Voltaire Foundation. 